\section{Artigos}

\title{
Cultura e Reversibilidade: breve reflexão sobre a abordagem "inventiva" de Roy Wagner"
}

\section{Luiz Felipe Rocha \\ Benites \\ (Museu Nacional/ \\ UFRJ)}

INTRODUÇÃO

O conceito de cultura faz parte do pensamento antropológico há muito tempo, e as reformulações pelas quais passou este conceito não estão desvinculadas de determinadas abordagens da prática antropológica. Neste artigo, não proponho reconstituir um campo de debates acerca das mutações e significados de tal conceito e o seu respectivo uso pelos antropólogos. Meu propósito é desenvolver um exercício de reflexão que tome a relação entre etnógrafo e "nativo" como dispositivo central de construção do conhecimento antropológico. Para tanto, busco inventariar alguns recursos conceituais e analíticos que enfatizam o caráter de "parceiros" (partners) entre o antropólogo e seus interlocutores "nativos" na produção do conhecimento antropológico, tal como propõem Harri Englund e James Leach (2000: 245). O exercício de reflexão em questão não se reduz, então, a um problema de escrita etnográfica, tal como o encara uma parte considerável da literatura pós-moderna em antropologia, mas estende seu alcance de problematização ao contexto da experiência etnográfica como forma de neutralizar os efeitos de oposição entre "experimentar lá" e "escrever aqui". Neste sentido, a concepção de cultura trabalhada por Roy Wagner (1981) constitui, enquanto conceito que evoca tanto a idéia de mediação quanto a de criatividade, o objeto a ser explorado precisamente porque permite lançar bases sólidas para um empreendimento antropológico nos termos citados acima. A obra deste antropólogo, ligado à Universidade da Virgínia (EUA), tem como referência etnográfica a pesquisa realizada por ele próprio com os Daribi da Nova Guiné e está inserida em um conjunto de estudos melanésios que tem proporcionado contribuições produtivas ao pensamento antropológico contemporâneo.

O aporte de Wagner encontra-se justamente na superação do termo cultura para designar qualquer entidade, unidade, estrutura, sistema, finalidade ou objeto da antropologia. Procurarei, pois, refletir sobre a contribuição que a noção de cultura proposta pelo autor pode oferecer para pensarmos as relações entre antropólogo e "nativo", na medida em que permite tomar os procedimentos de observador e observado como equivalentes e, por conseguinte, reconhecer como a própria posição de observador e observado pode ser, nos termos de Wagner, "reversa". 


\section{INVENTANDO CULTURA}

A idéia de que o homem inventa a sua realidade não é nova, reconhece Roy Wagner (1981). Contudo, como ele próprio assinala, esta perspectiva constitui uma dificuldade para uma antropologia e para uma cultura que buscam controlar sua própria realidade. Ainda segundo o autor, faz muito tempo que a disciplina antropológica está mais orientada para "rationalize contradiction, paradox, and dialectic, rather than to trace out and realize their implications" (Wagner 1981: x). A idéia aqui, então, é refletir sobre as implicações do conhecimento etnográfico e traçar um deslocamento de um modelo puramente de objetivação antropológica para um outro, calcado na criação e na invenção. A essa empresa dedicar-me-ei a seguir.

Wagner é herdeiro de uma tradição culturalista norte-americana que deriva de David Schneider. Sendo assim, ele não reivindica uma posição interpretativista, no sentido dado por Geertz (1989), ou qualquer outra que esteja situada nos campos do idealismo-pragmatismo, da fenomenologia, da etnometodologia ou de qualquer tipo de marxismo antropológico (Wagner 1981: xviii). Sua preocupação é muito pontual. Interessam-lhe os símbolos. Sua teoria da cultura é, entre outras coisas, uma teoria da simbolização. Segundo esta teoria, os símbolos não se relacionariam com nenhuma realidade externa a eles, mas somente com outros símbolos. Logo, nenhuma realidade guardaria qualquer tipo de externalidade em relação aos símbolos, pois estes não poderiam ser desconectados da percepção dela. O espaço em que os símbolos relacionam-se uns com os outros, em combinação infinita, é denominado "contexto". Aqui encontramos o primado relacional da teoria do autor: a relação precede os termos relacionados. Por conseguinte, o significado só pode ser pensado em suas relações, em seu contexto, já que os símbolos só adquirem algum sentido quando relacionados entre si.

Há dois modos de simbolização articulados à convencionalização e à invenção, através dos quais a cultura opera. A simbolização convencional estabelece relações entre elementos no interior de um campo discursivo, agregando os signos dentro de um determinado padrão, construindo uma rotulação ou codificação "dos detalhes do mundo" que é ordenado. Esta forma de simbolização convencionaliza associações, permitindo o compartilhamento dos símbolos e, assim, sua utilização como base para a comunicação entre agentes, produzindo a propriedade coletivizadora dos símbolos convencionais. É importante salientar que neste tipo de simbolização está delineado um contraste entre os símbolos em si mesmos e aquilo que eles simbolizam. O significado advindo de uma convenção é lexical, gramatical, expressa uma arbitrariedade. Desta forma, ele envolve uma tautologia (por exemplo, algo é considerado quente por oposição ao frio) e, por meio deste tipo de operação emergem os sistemas de classificação.

Há, contudo, um outro modo de simbolização denominado por Wagner de "diferenciante" ou "nãoconvencional", que constitui a outra face da simbolização convencional. Tal como ocorre na formação de uma metáfora, situação em que a introdução de um novo referente acompanha simultaneamente uma nova simbolização, neste outro modo, os símbolos assimilam ou englobam as coisas que simbolizam. A partir daí, é possível reconhecer que todo procedimento de natureza metafórica que envolve, de modo geral, um empreendimento inventivo, produz a extensão dos significados. Tal extensão de significados ultrapassa o registro tautológico imprimido pela convenção. A dinâmica metafórica da simbolização "diferenciante" compreende tanto 
uma não-arbitrariedade como uma relação indeterminada entre significante e significado. A metáfora colocaria, então, os símbolos em relação em um processo em que estes representariam apenas a si mesmos.

Nesta dinâmica, as simbolizações "convencional" e "diferenciante" delineiam o contexto de controle mútuo de uma e de outra, denotando uma relação de interdependência entre si. Desta forma, tal como referi anteriormente, os símbolos, para serem comunicados, devem ser compartilhados e, para isso, precisam produzir convenções, ou seja, toda sociedade precisa inventar convenções, já que são elas que dão consistência ao mundo. A convencionalização não impede a invenção, pelo contrário, incita-a. Temos aqui uma idéia de fluxo contínuo de invenções. Afinal, de acordo com o autor: "The necessity of invention is given by cultural convention, and the necessity of cultural convention is given by invention" (Wagner 1981: 52). Assim, a idéia de controle que a convenção pode carregar é apenas uma espécie de ilusão necessária, uma vez que as convenções são o suporte para as invenções e vice-versa.

Diante do exposto, podemos encarar a invenção cultural como um sucessivo processo de formação de metáforas, de associações e extensões de elementos simbólicos cujo sentido pode ser mais ou menos literal dependendo do contexto de controle. Nesta dinâmica, a cultura não só "objetifica" a realidade por meio de convenções como também a inventa a partir do simbolizar convencional.

Cabe salientar que na dialética sem síntese das simbolizações convencionais e não-convencionais há respectivas propriedades, coletivizantes e diferenciantes, cuja associação preponderante é possível estender, também respectivamente, às sociedades ocidentais e indígenas. Elas dizem respeito a como o inato e o construído são assumidos e equacionados por cada uma destas sociedades. Para os ocidentais, entre os quais predomina o modo coletivizante, o contexto não convencionalizado diz respeito à ordem natural que funciona como fundo (inato, dado) sobre o qual as ações humanas se orientam conforme as expectativas das convenções sociais. Já nos coletivos não-ocidentais, tal como a Melanésia, há predominância do modo diferenciante, o dado ou inato encontra-se justamente no domínio das convenções sociais e o que motiva a ação humana é o trabalho de individuação de pessoas e grupos. Vejamos o exemplo do casamento a que se refere Wagner no terceiro capítulo de seu livro. Para os americanos de classe média, as diferenças individuais são inatas (temperamento, personalidade, orientações sexuais etc.) e o casamento emerge como um arranjo que permite a interação a partir do compartilhamento de um determinado ideal estabelecido por convenções sociais. Já entre os melanésios, a aliança matrimonial é dada e o esforço é justamente o de individuação por meio de ações genderizadas, que fazem do casamento uma relação entre indivíduos, à medida que definem a condição masculina e feminina dos sujeitos.

Ainda que Roy Wagner carregue consigo a preocupação clássica do estruturalismo - a análise formal e relacional entre os símbolos - sua teoria do símbolo não é tributária de uma idéia de estrutura, tal como outras teorizações que derivam da abordagem de Saussure. Os processos de convencionalização e invenção não estão amarrados nem por estruturas inconscientes nem por estruturas culturais ou sociais. Tal como afirma o autor:

"Invention changes things, and convention resolves those changes into a recognizable world. But neither the distinctions of convention nor the operations of invention can be identified with some fixed 'mechanism' within the human mind, or with some kind of superorganic 'structure' imposed upon the human situation. All that we 
ever have is a set of orderings and articulations, relatively more or less conventionalized for every actor, which action represents to us in absolute terms as innate and an artificial, conventional and nonconventionalized. We participate in this world through its illusions, and as its illusions" (Wagner 1981: 53).

Diante do exposto, notamos que esta abordagem da invenção parece conectar-se mais a uma imagem artística do que a um construtivismo social calcado em estruturas ocultas que apenas o cientista social pode desvelar. Wagner, trilhando outros caminhos de entendimento ${ }^{2}$, associa o uso da expressão "invenção" à improvisação jazzística (Wagner 1981: 88), pois "like invention in music, it refers to a positive and expected component of human life" (Wagner 1981: xvi). Nesta acepção, todo ser humano inventa cultura, ou melhor, a invenção cultural é uma atividade vital de todos os seres humanos.

\section{SIMETRIZANDO PROCEDIMENTOS: A ANTROPOLOGIA REVERSA}

Se todo ser humano inventa cultura, por que, então, não encarar a antropologia como um empreendimento para além das objetivações que buscam um controle sobre a cultura? Não seria razoável pensar a cultura menos como código a ser seguido e mais como uma heterogeneidade de elementos que servem de base para a improvisação inventiva?

A abordagem wagneriana aponta para a antropologia como disciplina que inventa cultura a partir da cultura. O estudo da cultura também é cultura e, simultaneamente, a cultura é o instrumento para sua invenção. $\mathrm{O}$ autor extrai as implicações deste empreendimento da seguinte forma:

"The study of culture is in fact, our culture; it operates through our forms, creates in our terms, borrows our words and concepts for its meanings, and re-creates us through our efforts. (...) If our culture is creative, then the 'cultures' we study, as others' examples of this phenomenon, must also be. For every time we make others part of a 'reality' that we alone invent, denying their creativity by usurping the right to create, we use those people and their way of life and make them subservient to ourselves. And if creativity and invention emerge as the salient qualities of culture, then it is to these that our focus must now shift" (Wagner 1981: 16).

Levando-se em conta esta tomada de posição, percebe-se que o exercício de pensar a invenção da cultura pelo antropólogo passa por uma reflexão séria, principalmente a partir do estatuto da etnografia. De acordo com Wagner, o tipo de experiência criativa que é o trabalho de campo pode ser visto efetivamente como um trabalho, pois dele resulta um certo produto que é vendido sob a forma de "qualificações" no mercado acadêmico ou sob a forma da escrita de livros (1981: 17). Afinal, "the totality of the ethnographer's interest in 'culture' and the way he implements this interest in the field, then, is what defines his job as a fieldworker" (Wagner 1981: 18).

Na visão sacramentada por Malinowski (1978), a etnografia deveria consistir em uma investigação intensiva e de longa duração na qual o etnógrafo teria a necessidade de viver no local em que realiza o trabalho de campo, aprendendo a "língua nativa" e, assim, criando as condições para observar o cotidiano da vida dos "nativos" sem desprezar qualquer um de seus aspectos. O objetivo da etnografia consistiria, a partir desta perspectiva, em dar 
conta da totalidade da vida tribal por meio da reconstituição da estrutura social, do registro dos "imponderáveis da vida real e do comportamento típico" (Malinowski 1978: 31), assim como da apreensão do ponto de vista "nativo", enquanto expressão dos seus modos de pensar e sentir.

Se os cânones da pesquisa etnográfica preconizados por Malinowski não são objeto de consenso, é razoável, pelo menos, afirmar que uma das vantagens da etnografia consiste em tornar possível o ingresso do pesquisador no que Michael Herzfeld (1997) denominou de "intimidade cultural" (cultural intimacy). Esta "intimidade" corresponderia ao ingresso naquele ambiente em que se compartilham os sentimentos do que é embaraçoso e constrangedor entre os sujeitos pesquisados, por meio de um dispositivo de auto-reconhecimento "penoso" (rueful self-recognition). Compartilhar da intimidade cultural "nativa" é, então, o efeito da constituição de uma modalidade de relacionamento permanentemente negociada e limitada cujos desdobramentos modelarão indubitavelmente o conhecimento elaborado por meio da etnografia.

Marilyn Strathern (1999) sugere que as relações sociais estabelecidas em campo devem ser valorizadas em si mesmas, pois delas deriva o conhecimento que o etnógrafo produz. Desta forma, podemos afirmar que as relações sociais constituem o conhecimento anterior à busca e à codificação deste mesmo conhecimento. Isto é, o trabalho de campo, em seus dois momentos - o de campo, propriamente dito, e o de gabinete, ou seja, o de escrita - desenvolve-se no sentido da relação ao conhecimento, para que se possa fazer o movimento posterior de retorno do conhecimento às relações que descrevemos.

A vivência do trabalho de campo e a sua posterior "reterritorialização" nos escritos etnográficos é mais produtiva na medida em que o pesquisador se permite o que Favret-Saada (1990) chamou de "ser afetado" (être affecté). A autora concebe este estado como uma modalidade de experimentação de intensidades específicas (os afetos), somente possível a partir da ocupação e do acesso a determinados lugares a partir dos quais se estabelece uma comunicação específica com os sujeitos estudados que não é passível de representação. Não se trata da "transformação" do pesquisador em "nativo": o que está em jogo é situar-se, ocupar um local em que se possa ser afetado pelas mesmas forças que incidem sobre os nativos. Por outro lado, aceitar ocupar esse lugar não informa exatamente sobre as afecções do outro, mas sobre o que afeta o próprio pesquisador nesta posição em que o outro o colocou. É este ato de ser afetado que abre a referida comunicação específica de que fala a autora: comunicação ao mesmo tempo involuntária e sem intenção, verbalizável ou não, com o outro (Favret-Saada 1990: 6).

Se o "afetar-se" está relacionado à ocupação de determinados lugares durante o trabalho de campo, seria razoável admitir que a noção, que apresentarei a seguir, de "antropologia reversa" desenvolvida por Wagner é resultado do diálogo com as obras de outros antropólogos melanesistas que descreveram cargo cults, mas também, em certa medida, fruto de uma posição ou lugar no qual ele foi colocado pelos Daribi, ou seja, é também produto de uma relação que foi estabelecida no contexto do seu trabalho de campo. Seus amigos "nativos" consideravam curiosa sua situação. Não tinha esposa e contratava um cozinheiro. Era indiferente aos problemas da vida prática, mas alimentava uma paixão por entrevistas. Quando lhe perguntavam se estava unido ao governo e aos missionários, afirmava que não, embora pudesse estar, e que seu interesse era da ordem da disciplina em que trabalhava (antropologia). Contudo, esta pergunta foi refeita, posteriormente, sob outra forma pelos Daribis: 
haveria "nativos" (kanakas) como eles na América? Sua resposta positiva, ao fazer alusão a populações tuteladas, como os agricultores de subsistência, não convenceu nem a ele próprio.

Wagner havia percebido que os Daribi realizavam operações analíticas similares às dos antropólogos. Os Daribi tentavam conferir sentido à presença de Wagner entre eles e, portanto, demonstravam uma preocupação com um modo de relacionar-se com a alteridade que se delineou com a referida experiência. Levando em consideração esta experiência e, sobretudo, os estudos de Lawrence (1964) e Burridge (1970) que tentam dar conta do choque gerado pelo contexto colonial do século XIX entre as populações melanésias e ocidentais, Wagner refletiu sobre a possibilidade de literalizar as metáforas da "civilização moderna industrial" do ponto de vista de uma sociedade tribal. Tal procedimento intelectual, inovador na relação com o ponto de vista "nativo", foi o que ele denominou de "antropologia reversa" (reverse anthropology). O autor experimenta, então, o uso do pensamento melanésio personificado nos cargo cults - isto é, o culto das mercadorias européias enquanto objetos sagrados e cujas associações ganhavam cores apocalípticas e milenaristas - como reverso da idéia de "cultura". Isto significa que:

“(...) we look at natives' cargo, their techniques and artifacts, and call it 'culture', whereas they look at our culture and call it cargo. (...) 'Cargo' is practically a parody, a reduction of Western notions like profit, wage-labor, and production for its own sake to terms of tribal society. (...) Cargo is really an antisymbol to 'culture'; it metaphorizes the sterile orders of technique and 'self-fulfilling' production as life and human relation, just as 'culture' does the reverse" (Wagner1981: 31-32).

Desta forma, cultura e cargo metaforizariam uma mesma relação entre sociedades em direções diferentes. Wagner representa uma cultura em que trabalho, técnica e produtividade ocupam um lugar central no sistema de valores. A lógica ocidental opera pela acumulação e os produtos, as técnicas e artefatos costumam ser objetificados como "cultura" e esta costuma ser preservada (outra preocupação ocidental) em museus, livros etc. O modo de vida melanésio parece personificar justamente o inverso, na medida em que tais elementos são agenciados de forma invertida nas suas práticas de sentido. O Kago, expressão melanésia para as mercadorias ocidentais, representa a riqueza material cujo acesso objetifica as relações sociais. Esta inversão, entretanto, não é trivial.

A palavra "cultura" marca uma relação e a antropologia é menos análise ou exame da relação entre culturas do que, propriamente, relação entre culturas. Daí o caráter mediador do conceito. Devo lembrar que a noção de cultura não faz parte das técnicas de conhecimento, ou seja, dos recursos conceituais, dos melanésios, mas constitui uma invenção, no sentido criativo, do antropólogo, para dar inteligibilidade à vivência com os sujeitos que ele estuda. Conforme Wagner, o etnógrafo experimenta a diferença no campo, procedendo como se a diferença resultasse de um contraste entre a sua cultura e a do "nativo". Por meio deste procedimento de entendimento, via diagnóstico da diferença, ele acaba "inventando cultura".

Em toda relação que envolve a pesquisa antropológica, aqueles que estudamos também pensam e buscam dar sentido à nossa presença entre eles e, conseqüentemente, buscam dar sentido à nossa cultura. $O$ sentido conferido ao que cada um faz, o antropólogo e o "nativo", é construído por cada uma das partes, por intermédio do processo inventivo de que Wagner fala, isto é, por meio de sucessivas formações de metáforas 
produzidas quando se busca estender o significado dos elementos simbólicos convencionados em suas técnicas de conhecimento. Neste sentido, a cultura - entendida como produto derivado do choque entre a sociedade do antropólogo com a do "outro", para pensar a alteridade - estenderia o significado da técnica e do artefato para as relações e pensamentos humanos, enquanto o seu reverso, o cargo cult - entendido como produto da experiência do antropólogo em sua relação com os melanésios, através do qual ele pensa a sua própria sociedade-estenderia o sentido das relações humanas e da produção mútua para os artefatos manufaturados.

Wagner demonstra, portanto, que os melanésios também praticam antropologia, isto é, eles também elaboram práticas de sentido para conferir inteligibilidade às suas experiências de alteridade. Certamente esta antropologia não é a mesma que praticamos. Ciente disto, o antropólogo norte-americano nomeou esta antropologia feita pelos melanésios de "antropologia reversa". O mérito do autor, ao apropriar-se da idéia de cargo cult como reverso da idéia de cultura, foi ter experimentado um (outro) pensamento, tal como exporei adiante, a partir da sua experiência etnográfica. O reconhecimento etnográfico dos procedimentos de uma "antropologia reversa" institui um tratamento simétrico, na acepção de Bruno Latour (1994), e, por isso, trabalha para superar o grande divisor "nós/eles" de forma ousada. Sua ousadia refere-se ao fato de propor não que "todos somos nativos", mas que "todos somos antropólogos" e, portanto, a etnografia que praticamos deve estar aberta à criatividade daqueles que estudamos.

\section{EXTRAINDO ALGUMAS IMPLICACÕES}

Quando assumo a perspectiva inventiva descrita por Wagner, afasto-me de qualquer discussão sobre abordagens que busquem o que está oculto por trás de palavras ou práticas. Concordo com Thomas Csordas quando ele diz que "we must recognize explicitly that the problem of evidence is in essence a problem of speech in relation to experience" (Csordas 2004: 479). Se o debate acerca das evidências pode ser encarado como um problema da relação entre experiência no campo e formulação do discurso etnográfico, a atitude mais produtiva é enfrentar seriamente o desafio da construção ficcional da etnografia. Eduardo Viveiros de Castro (2002) situa com precisão o significado deste empreendimento ao articular o que denomina de "exercício de ficção antropológica" a uma determinada "experiência de pensamento":

“A expressão 'experiência de pensamento' não tem aqui o sentido usual de entrada imaginária na experiência pelo (próprio) pensamento, mas o de entrada no (outro) pensamento pela experiência real: não se trata de imaginar uma experiência mas de experimentar uma imaginação. A experiência, no caso, é a minha própria como etnógrafo e leitor da bibliografia sobre a Amazônia indígena, e o experimento, uma ficção controlada por essa experiência. Ou seja, a ficção é antropológica, mas sua antropologia não é fictícia" (Viveiros de Castro 2002: 123).

O modo como Viveiros de Castro encara esta dimensão ficcional da etnografia é necessário para "pôr em ressonância interna dois pontos de vista completamente heterogêneos" (Viveiros de Castro 2002: 123). Tal como coloca Strathern (1987), é a partir da relação entre tais pontos de vista, o do antropólogo e do "nativo", ou melhor, da relação entre estas duas técnicas de teorizar que emerge relacionalmente o conhecimento antropológico. 
Cabe salientar que tal relação pode ser remetida a uma experiência de "afetar-se", no sentido dado por FavretSaada (1990), entre modalidades distintas de pensamento. Portanto, o que está em jogo não é a assunção do ponto de vista do "nativo", mas o reconhecimento de que a descrição do antropólogo deriva do ponto de vista da sua relação com o ponto de vista "nativo" (Viveiros de Castro 2002: 123).

Diante do exposto, podemos encarar o discurso antropológico como "práticas de sentido", isto é, como relação de sentido com outros discursos (Viveiros de Castro 2002) ou, ainda, como "troca de perspectivas" (Strathern 1999). Ambas as visões operam em sintonia com o princípio da invenção da cultura por meio da cultura de que fala Wagner. Contudo, uma questão surge destas perspectivas: a relação que o nativo tem com o seu discurso seria a mesma que o antropólogo tem com o seu? Strathern (1987), a partir da sua experiência com as modalidades de conhecimento melanésio, afirma que não, pois os melanésios não possuíam, por exemplo, entre suas técnicas de conhecimento, noções como as de cultura ou de sociedade para pensarem a si mesmos.

Reconhecendo as implicações da possibilidade de uma "antropologia reversa" nos termos descritos por Wagner (1981), a questão colocada acima pode ser tomada a partir da relação que produzem as próprias posições de antropólogo e nativo, ou seja, de "observador" e "observado". Viveiros de Castro remete tal construção de posições a um jogo de linguagem freqüentemente 'em elaboração' pelo etnógrafo no seu trabalho de descrição:

“O que faz do nativo um nativo é a pressuposição, por parte do antropólogo, de que a relação do primeiro com a sua cultura é natural, isto é, intrínseca e espontânea, e, se possível, não reflexiva; melhor ainda se for inconsciente. O nativo exprime sua cultura em seu discurso; o antropólogo também, mas se ele pretende ser outra coisa que um nativo, deve poder exprimir sua cultura culturalmente, isto é, reflexiva, condicional e conscientemente. Sua cultura se acha contida, nas duas acepções da palavra, na relação de sentido que seu discurso estabelece com o discurso nativo. Já o discurso do nativo, este está contido univocamente, encerrado em sua própria cultura. O antropólogo usa necessariamente sua cultura; o nativo é suficientemente usado pela sua" (Viveiros de Castro 2002: 114).

Mas o que acontece quando o antropólogo está imerso na mesma cultura, isto é, quando ele sente o efeito do compartilhamento de convenções com os sujeitos que ele pesquisa? O problema se torna mais complexo ao levar-se em conta outra questão, elaborada por Strathern (1987) ao referir-se à possibilidade de uma auto-antropologia: o que é estar em casa? Ciente da dificuldade da questão e da necessidade de mantê-la em aberto, permanentemente no processo de pesquisa, a própria autora ensaia um encaminhamento: "Whether anthropologists are at home qua anthropologists (...) is decided by the relationship between their techniques of organizing knowledge and how people organize knowledge about themselves" (Strathern 1987: 31).

Um caso interessante, e presente em muitas investigações antropológicas, diz respeito à "politização" de conceitos que muitas vezes fazem parte do repertório analítico dos próprios antropólogos, como a própria noção de cultura, pelos "nativos". Quando falo em "politização" me refiro ao fenômeno assim descrito por Susan Wright:

"In the last decade, politicians and decision-makers have introduced 'culture' into the discourse of many different 'fields' (Bourdieu 1991) of contemporary society. Decision-makers and media commentators often claim legitimacy for their discourses by referring to 'culture, in an anthropological sense' - a phrase which closes off further exploration by claiming that there is one (their) meaning of culture which is at once too self-evident to warrant explanation and too deep to be delved into by non-anthropologists" (Wright 1998: 78). 
Não creio poder esgotar as possibilidades de enfrentar esta situação que levantei, mas posso sugerir alguns elementos para pensá-la diante do que expus até agora. Primeiramente, não basta afirmar que todos os sujeitos sociais teorizam, tal como o faz Anthony Giddens. Marilyn Strathern (1987), em sua crítica ao referido autor, chama a atenção para o modo como são colocadas em relação nossas técnicas de conhecimento/teorização e as daqueles que pesquisamos, tal como me referi anteriormente. É preciso observar que terreno há de comum entre tais técnicas conceituais. Desta forma, tal "politização" da noção de cultura pode ser pensada a partir do efeito de múltiplas relações entre o conhecimento manipulado pelo antropólogo e o conhecimento daqueles que entram em interlocução com o conhecimento do antropólogo, nos contextos de distintas experiências.

Lembrando Wagner, devemos estar atentos às associações e seus respectivos contextos, que estão sendo carregados junto com o conceito de cultura em jogo. A invenção de novos sentidos sempre parte de convenções existentes, compartilhadas pelos indivíduos em questão. O problema é compreender como, por meio do modo de simbolização diferenciante, os sentidos da idéia de cultura vão sendo estendidos a partir de sucessivos processos metaforizantes. Em uma perspectiva complementar, suscitada pela reflexão de Latour (2005), uma tarefa interessante pode ser a de traçar uma rede de associações na qual sejam mostradas, em diferentes momentos, as mudanças que o conceito de cultura sofre a partir das traduções pragmáticas que cada mediador do conceito efetua.

Um dos efeitos possíveis da relação entre as perspectivas do antropólogo e do nativo é o de revival. 0 próprio Wagner, ainda no debate sobre os "cargo cults", trata disso (1981: 33-34) ao expor o caso descrito por Peter Lawrence sobre Yali, uma liderança melanésia que em 1947 cooperava com a administração colonial e a partir deste contato estabelece algumas interpretações sobre os ocidentais e sobre seu próprio povo. Wagner chama atenção para a reação de Yali com o modo ocidental de preservação do passado ao visitar um museu em que ele teria observado, nestes termos, que os "mitos" de seu povo ali também se encontravam. Wagner salienta que, segundo Lawrence, a palavra "mito" (perambiki, sitori) tinha naquele contexto o sentido de "cultura da Nova Guiné". Yali, ao retornar a sua tribo, teria dado início a um revival em larga escala de cerimônias tradicionais relativas ao cargo. Tais revivals, realizáveis em qualquer lugar do mundo, segundo o autor, não diriam respeito à cultura em si mesma. Mesmo nos casos em que a cultura é assumida conscientemente, isto é, mesmo nas situações em que a identidade encontra-se envolvida, esta não exaure os usos da cultura. Para Wagner, nestes casos de revival, e eu arriscaria afirmar que em outros usos da noção de cultura, a cultura não faz senão dar acesso a outras coisas mais importantes que ela mesma.

Nesta perspectiva é preciso evitar o desejo de encontrar incoerências ou contradições no discurso "nativo" que lança mão de conceitos como cultura, raça, etnia etc. Certamente é fácil declarar tal empreendimento como princípio, contudo, nem sempre é fácil executá-lo. O desafio é tentar que o antropólogo não arrogue a si a postura de juiz que vai avaliar qual o conceito utilizado pelos sujeitos que ele pesquisa é o mais adequado. Encontrar inconsistências entre discursos, ou entre discursos e práticas dos atores, remete ao não reconhecimento por parte do investigador de que todo discurso constitui uma prática de sentido. Dentro da abordagem exposta, o problema de consistência é do antropólogo na construção da descrição etnográfica e não dos modos de existência do "nativo". Em uma ficção controlada pela experiência, a descrição etnográfica é tão mais rica quanto mais conseguir compor meticulosamente um plano que confira consistência às práticas de sentido do "outro". 


\section{CONSIDERAÇÕES FINAIS}

Roy Wagner desenvolveu uma noção de cultura que se afasta de características estruturais ou sistêmicas e assume a criatividade como elemento central de sua elaboração teórica. A partir desse princípio operativo, ele propõe a invenção como uma atividade humana vital. Nesta proposição há duas implicações da idéia de cultura proposta pelo autor: a objetividade relativa (relativity objectivity) e a relatividade cultural (cultural relativity). A idéia de objetividade relativa não é apenas uma recusa à idéia clássica de objetividade absoluta e, portanto, a afirmação de uma objetividade deficiente. Ela diz respeito ao fato de que todos observamos a partir dos pontos de vista da cultura a qual pertencemos. Relatividade cultural não significa relativismo cultural, isto é, a relatividade não diz respeito à idéia de que há uma realidade exterior aos símbolos e vários pontos de vista sobre a mesma. A relatividade cultural está combinada à objetividade relativa pois, se observador e observado pertencem cada qual a uma cultura e, portanto, só podem enxergar a partir dela, todas as culturas se equivalem.

Se reconhecermos a equivalência entre culturas, podemos extrair um princípio de pensamento simétrico, no sentido conferido por Latour (1994), de que, tal como nós, os "nativos" vivem conforme os pressupostos que eles mesmos inventam. Tal princípio simétrico não ignora as diferenças existentes, pois, assim como nós, eles possuem suas próprias idéias. O desafio é não abandonar a idéia de levar a sério os atores que pesquisamos na difícil e tensa busca de construir um discurso que não é o mesmo deles, mas que nem por isso se coloque como hierarquicamente superior ao "discurso nativo".

$\mathrm{Na}$ acepção de Latour (2005), não devemos proceder como o "sociólogo crítico" que é polido na relação com os indivíduos que pesquisa para, em seguida, no momento em que não está mais entre estes, abandonar o ponto de vista dos mesmos em favor da objetivação, a partir unicamente do seu ponto de vista de observador. De acordo com o autor, a reflexividade do analista é tributária da reflexividade dos atores, ou seja, "as a rule, it's much better to set up as the default position that the inquirer is always one reflexive loop behind those they study" (Latour 2005: 33). Recusando esta postura, trata-se, então, de aprender com os "nativos" e não repetir o que eles ensinam.

Diante do exposto, compartilhar as esferas da "intimidade cultural" deve proporcionar o acesso não a alguma verdade oculta, mas a outras relações de sentido que não emergem diretamente nos discursos nativos estandardizados. Se o etnógrafo não "tirar proveito" desta situação, estará limitado à reprodução do discurso que legitimamente os sujeitos investigados usam para obter reconhecimento em diferentes instâncias. A “intimidade cultural" em questão vincula-se à imersão de que fala Strathern (1999), isto é, à valorização das relações que estabelecemos em campo em si mesmas, para depois, em um cuidadoso trabalho de descrição, construir o conhecimento sobre as relações sociais que conseguimos extrair do traçado estabelecido a partir do material coletado em campo. Tal valorização inscreve-se na proposição de Englund e Leach (2000) de deixar que o contexto da relação que experimentamos em campo seja construído pelos nossos interlocutores "nativos".

A aceitação deste cenário pode permitir, por um lado, que, no momento da elaboração da descrição etnográfica, o efeito da nossa presença em campo possa se tornar visível e devidamente entendido. O referido efeito pode estar, entre outras coisas, no quanto contribuímos para a construção do sentido de termos (cultura, 
raça, etnia, gênero etc.) que são apropriados do nosso léxico conceitual pelos nossos interlocutores ou, ainda, que são tomados de outros lugares, sendo re-significados pela experiência de relacionamento entre o conhecimento do etnógrafo e o dos "nativos".

A experiência em questão também pode proporcionar a expansão do sentido da invenção cultural que produzimos por meio da abertura do nosso pensamento para a criatividade "nativa". Neste sentido, uma sugestão de Goldman (1999), concebida a partir de uma idéia de Guimarães Rosa, pode iluminar um caminho possível neste empreendimento. No prefácio de uma obra húngara traduzida por um amigo seu, Guimarães Rosa faz referência à inevitável traição da língua no processo de tradução. A proposta do escritor é, por paradoxal que possa parecer esta leitura, ética: o tradutor deve se permitir uma "fecundante corrupção", isto é, trair, contaminar o seu próprio idioma, corrompê-lo por meio da língua que deveria ser traduzida. Trata-se, pois, de uma ética da subversão, de reversão da condição inicial da relação entre "língua traduzida" e "língua tradutora".

Tal primado pode ser introduzido na prática antropológica, da seguinte forma:

“(...) se levarmos em conta que o trabalho antropológico é freqüentemente assimilado a uma forma de tradução cultural, o modelo de Rosa pode ser legitimamente ampliado: expandir e ampliar uma língua através de outra, estrangeira, pode significar expandir e aprofundar uma experiência cultural através da outra, igualmente estrangeira. Nesse sentido, o que os antropólogos fazem, ou poderiam fazer é praticar uma 'fecundante corrupção', expandindo e enriquecendo nossa própria cultura ao trazer à luz variáveis que certamente estão presentes aqui, mas que quase não aparecem, seja por que estão ocultas ou reprimidas, seja porque nos encontramos em uma posição que não nos permite enxergá-las" (Goldman 1999: 80).

A enriquecedora "corrupção" do saber antropológico pelo modo de pensar dos sujeitos pesquisados constitui um modo de fazer o discurso "nativo" agir no interior do discurso do etnógrafo. Em outras palavras, o trabalho de tradução cultural do antropólogo é, acima de tudo, um trabalho criativo de invenção. Assim, evocando Viveiros de Castro (2002), não neutralizamos o pensamento "nativo" tal como quando o tratamos como crença, mas o potencializamos enquanto atividade de simbolização ou prática de sentido. Ao invés do exercício de controle sobre a "realidade", para relembrar a dificuldade da antropologia apontada por Wagner, talvez devêssemos experimentar multiplicá-la, expandindo seu sentido na descrição de mundo que produzimos, através da proliferação em nosso texto da criatividade inscrita nas técnicas de conhecimento dos atores com quem entramos em relação no trabalho de campo. A "antropologia reversa", cunhada pelo antropólogo norteamericano, é um exemplo desta experiência de pensamento. Ela aponta para a extensão do significado da antropologia enquanto modalidade de relacionamento com a alteridade produzível em qualquer coletivo humano, assim como nos proporciona recursos profícuos, a partir de uma espécie de "engenharia intelectual reversa", para refletirmos sobre a construção de nossas operações de conhecimento. A tarefa antropológica de invenção cultural, nestes termos, é tanto mais complexa quanto mais experimentamos o esforço de ultrapassar estas declarações de princípio para efetuá-las no fazer etnográfico.

Luiz Felipe Rocha Benites é mestre em Sociologia pela Universidade Federal do Rio Grande do Sul e doutorando em Antropologia Social pelo Museu Nacional/ Universidade Federal do Rio de Janeiro. 


\section{NOTAS}

1 Este artigo é uma versão modificada de uma comunicação originalmente apresentada no GT "Observando os(as) observadores(as): cultura, raça, etnia e noções correlatas no saber/fazer antropológico", na 25a Reunião Brasileira de Antropologia, realizada entre 11 e 14 de junho de 2006, em Goiânia.

2 A obra de outros autores, como Bruno Latour e Marilyn Strathern, pode ser conectada, com as devidas especificidades, à abordagem "inventiva" proposta por Wagner. Reflexões como as de Strathern (1988; 1999) e do próprio Wagner (1991) que envolvem a noção de pessoa melanésia, tomada enquanto produto de relações integralmente nela implicadas, assim como as de Latour (1988) acerca da rede sócio-técnica que produz os micróbios "descobertos" por Luís Pasteur, são exemplos da criatividade dos sujeitos estudados, mas também da criatividade do investigador. 


\section{REFERÊNCIAS BIBLIOGRÁFICAS}

BURRIDGE, Kenelm. 1970. Mambu: A Study of Melanesian Cargo Movements and Their Ideological Background. New York: Harper \& Row.

ENGLUND, Harri \& James LEACH. 2000. “Ethnography and the Meta-Narratives of Modernity”. Current Anthropology 41: 225-248.

FAVRET-SAADA, Jeanne. 1990. "Être Affecté". Gradhiva 8: 3-9.

GEERTZ, Clifford. 1989. A Interpretação das Culturas. Rio de Janeiro: LTC.

GOLDMAN, Marcio. 1999. “O que Fazer com Selvagens, Bárbaros e Civilizados?” In Alguma Antropologia. Rio de Janeiro: Relume-Dumará.

HERZFELD, Michael. 1997. Cultural Intimacy: Social Poetics in the Nation-State. New York: Routledge.

LATOUR, Bruno. 1988. The Pasteurization of France. Cambridge, Massachusetts: Harvard University Press. . 1994. Jamais Fomos Modernos. São Paulo: Ed. 34.

Press. 2005. Reassembling the Social: An Introduction to Actor-Network-Theory. Oxford/New York: Oxford University

LAWRENCE, Peter. 1964. Road Belong Cargo: A Study of the Cargo Movement in the Southern Madang District, New Guinea. Manchester: Manchester University Press.

MALINOWSKI, Bronislaw. 1978. Os Argonautas do Pacífico Ocidental: Um Relato do Empreendimento e da Aventura dos Nativos nos Arquipélagos da Nova Guiné Melanésia. São Paulo: Abril Cultural (Coleção Os Pensadores).

STRATHERN, Marilyn. 1987. "The Limits of Auto-Anthropology". In A. Jackson (ed.) Anthropology at Home. London: Tavistock Publications.

. 1988. The Gender of the Gift: Problems with Women and Problems with Society in Melanesia. University of California Press.

. 1999. Property Substance and Effect: Anthropological Essays on Persons and Things. London: Athlone Press.

VIVEIROS DE CASTRO, Eduardo. 2002. “O Nativo Relativo”. Mana 8(1): 113-148.

WAGNER, Roy. 1981. The Invention of Culture. Chicago: The University of Chicago Press.

. 1991. "The Fractal Person". In Maurice Godelier \& Marilyn Strathern (eds.) Big Men and Great Men: Personification of Power in Melanesia. Cambridge: Cambridge University Press.

WRIGHT, Susan. 1998. "The Politicization of 'Culture'”. Journal of the Royal Anthropological Institute 14(1): 7-15. 
Cultura e Reversibilidade: breve reflexão sobre a abordagem “inventiva” de Roy Wagner RESUMO

Em meados da década de 1970, Roy Wagner, no seu livro The Invention of Culture, toma a antropologia como disciplina que inventa a cultura a partir da cultura. Alicerçado na sua experiência de campo com os Daribi, da Nova Guiné, o autor apresenta a noção de cultura como atividade criativa, na qual somos todos agentes inventivos. Nesta perspectiva, antropólogo e "nativo" realizam operações similares e, por conseguinte, o estudo da cultura consistiria na cultura do antropólogo. É ainda nesta obra que Wagner cunha o termo "antropologia reversa", para pôr em questão a posição privilegiada do etnógrafo no que diz respeito à elaboração de uma "análise antropológica". Diante do exposto, este artigo busca refletir sobre algumas implicações da adoção de tal perspectiva em antropologia, conectando-a a alguns debates contemporâneos da disciplina, principalmente sobre eixos como a dicotomia "nós/eles" e sobre o estatuto da etnografia.

PALAVRAS-CHAVE: cultura, invenção, antropologia reversa, conhecimento antropológico.

\section{Culture and Reversibility: a brief reflection about the "inventive" approach of Roy Wagner}

\section{ABSTRACT}

In the mid 1970s, Roy Wagner, in his book The Invention of Culture, sees anthropology as a discipline that invents culture through culture. Based on his experience with the Daribi of New Guinea, the author presents a conception of culture as a creative activity in which we are all inventors. In this perspective, the anthropologist and native perform similar operations and, consequently, the study of culture consists of the culture of the anthropologist. Wagner also coins the term "reverse anthropology" in order to question the ethnographer's privileged position regarding the elaboration of an "anthropological analysis". The present article seeks a reflection on some implications of the adoption of this perspective in anthropology, linking it with contemporary discussions, especially with regard to the us/them dichotomy and the statutes of ethnography.

KEYWORDS: culture, invention, reverse anthropology, anthropological knowledge. 